\title{
The concept of medicalisation reassessed: a response to Joan Busfield
}

\section{Simon J. Williams ${ }^{1}$, Catherine Coveney $^{2}$ and Jonathan Gabe ${ }^{3}$}

\author{
${ }^{1}$ Department of Sociology, University of Warwick, Coventry, UK \\ ${ }^{2}$ Centre for Global Heath Policy, University of Sussex, Brighton, UK \\ ${ }^{3}$ Criminology and Sociology, School of Law, Royal Holloway, University of London, London, \\ $U K$
}

Joan Busfield's (2017) reassessment of the concept of medicalisation is a welcome and timely contribution to a key issue within medical sociology, past and present. Not simply medical sociology however. Medicalisation indeed, as Conrad (2015) himself notes, now carries 'analytical weight' in a range of disciplines beyond sociology including history, anthropology, bioethics, economics, media studies and feminism. To this of course we may add engagements within medicine itself as well as the wider circulation of 'medicalisation' within popular culture, if not public consciousness today, as a commonly used if not abused term of reference, thereby rending medicalisation a victim of its own success perhaps. Hence debates in recent years as to whether or not medicalisation has outlived its usefulness as a concept, including its relationship to other newly developed concepts and ways of theorising these matters, in sociology and beyond (Bell and Figert 2014, 2015, Rose 2007).

Busfield, in this respect, does us a great service, not simply through retracing the archaeology of the concept within medical sociology from the 1970s onwards, but also through her valuable defence of the concept and its future in sociological analysis. Particularly valuable in this respect, in our view, are: (i) Busfield's reminders of the various ways in which the positive aspects of medicalisation have in fact been emphasised within existing work, sometimes albeit only in passing or as a point of departure before launching into the negatives; (ii) her drawing out the problems and limits of various critiques of medicalisation, and; (iii) her argument that questioning specific cases of medicalisation as 'illegitimate' cannot and should not be read as questioning the value of medicine as such, or as claiming that any and all instances of medicalisation are unacceptable.

For all its merits, however, Busfield's paper rests on a somewhat partial and problematic engagement with and reading of these matters, in places at least, particularly when it comes to matters of: (i) conceptual coverage; (ii) conflationary charges; (iii) new concepts, and; (iv) developing directions. These problems, to be fair, may be inevitable to a degree, given the vast corpus of literature bearing on these matters since the 1970s, though this alone cannot explain the points we raise below.

Taking each of these matters in turn then, whilst Busfield clearly attends to definitional issues in her paper concerning the concept in question, she fails to fully articulate or elaborate upon the different dimensions and directions of medicalisation in doing so. Medicalisation after all, as Conrad $(1992,2007,2015)$ reminds us, may occur on different levels (conceptual, institutional, interactional) and to different degrees, from the fully medicalised to the minimally medicalised. It is also, of course, a bidirectional process, including the potential not simply for the medicalisation but the demedicalisation or even the remedicalisation of a human condition 
or problem over time. Medicalised categories, in this respect, are 'elastic' in the sense that they can expand or contract over time (Conrad 2015: viii). Medicalisation research moreover, in Conrad's (2015: vii) view, 'does not adjudicate whether or not an entity is "really" a medical problem, but rather how it became [sic] to be depicted (and accepted) as a medical problem and with what consequences'. This is important to stress, not simply for pedantic reasons, nor even simply in the interests of a fuller elaboration and reassessment of the concept in question, important as that is, but as part and parcel of the very defence of the concept that Busfield seeks to mount in the face of various so-called 'alternatives' - though whether any such defence is necessary and whether in fact these are really 'alternatives' in the first place is also something we will return to later.

If this first point then concerns 'conceptual coverage', the second point involves the closely related matter of 'conflationary charges' on Busfield's part. While she is right of course to point these matters out - including the dangers of conflating imperialism with medicalisation, and the dangers of conflating medicalisation solely or simply with 'illegitimate expansion' - it is also surely incumbent on her in any such archaeology of these debates, to point out rather than glide or gloss over the fact that these dangers have long since been aired if not laid to rest within the history of medical sociology itself once and for all, thereby rendering the charge somewhat redundant now. Conrad and Schneider (1980) for example, in their response to Strong's (1979) original paper, note how allegations of imperialism are ultimately irrelevant to the medicalisation argument or thesis as such. Williams (2001) too, in revisiting Strong's paper, does not simply repeat these conflations as Busfield claims, but rehearses these very debates in the interests of further clarifying these matters in the process for future reference; points moreover he has rehearsed ever since (see for example Williams 2004, Williams and Gabe 2015). Strong then may be guilty of such conflation, but any such charges have long since been laid to rest, both at the time of Strong's original paper and subsequently. The general thrust of Strong's critique anyway, it should be noted, was less about medical imperialism and more, in a reflexive fashion, about 'sociological' imperialism, irrelevant or otherwise, when it came to sociology's medicalisation critique. Again it is strange that Busfield misses this point, since it shows a welcome degree of reflexivity on the part of sociologists, Strong included, in using this very concept: something again we shall return to in terms of future agendas.

A third critical issue concerns another recent concept that Busfield leaves out of her assessment of this changing landscape of challenges to and critiques of medicalisation. Whilst Rose's (2007) critique is discussed, as is Clarke et al.'s (2003, 2010) notion of biomedicalization, Moynihan and colleagues' (Moynihan et al. 2002, Moynihan and Henry 2006) arguments on so-called disease mongering or the selling of sickness are oddly omitted. Odd because some cases of medicalisation, Moynihan et al. (2002) claim, are now better described or understood as cases of outright 'disease mongering' in which the 'social construction of illness' has given way to the 'corporate construction of disease'. Hence these claims, whatever one makes of them, should surely weigh somewhere on the balance sheet in any reassessment of the concept of medicalisation. This indeed is all the more important in our view given that these debates on disease mongering seem to have gained some traction within prestigious journals such as the British Medical Journal (Moynihan et al. 2002) as well as the Public Library of Science Medicine (Moynihan and Henry 2006). Perhaps most importantly in the present context, some assessment of these disease mongering arguments provides a further opportunity not simply to reassess but to reassert the value of medicalisation as a concept, precisely because medicalisation, for the likes of Conrad $(1992,2007)$ as well as us (Williams and Gabe 2015), is a descriptive value neutral term, unlike disease mongering which as the very term suggests is a value laden concept with an inbuilt element of social critique. 
This in turn brings us to a fourth key point concerning the merits of pharmaceuticalisation as another relevant concept which Busfield discusses but then, somewhat surprisingly indeed given her own long standing interest in pharmaceuticals, largely writes off on the grounds that it has little or no analytical value beyond what medicalisation already offers. As advocates of this concept ourselves (Gabe et al. 2015, Williams, Martin, and Gabe 2011) together with the likes of Abraham (2010), we beg to differ. Busfield argues that pharmaceuticalisation does not provide an 'adequate alternative' to medicalisation and 'does not diminish the value' of the concept, seeing each as parallel terms. For us pharmaceuticalisation is considered not so much an 'alternative', 'competing' or 'parallel' concept that precludes or diminishes medicalisation, but rather a complementary or related conceptual tool, albeit one with complex, dynamic relations to medicalisation. Like medicalisation moreover, in contrast to disease mongering, pharmaceuticalisation as we define it is a descriptive, value neutral term, which denotes the translation and transformation of human conditions or problems into opportunities for pharmaceutical intervention (Gabe et al. 2015, Williams, Martin, and Gabe 2011). The gains as well as losses of these processes must also be judged on a case by case basis, including the potential, in keeping with the bi-directional nature of medicalisation, for some degree of 'depharmaceuticalisation' over time.

Perhaps most importantly and succinctly of all, the value of the concept as we see it, is not simply a product of the fact that not all cases of medicalisation involve pharmaceuticalisation, though many do of course (including say pain killers following surgery), but that not all cases of pharmaceuticalisation involve medicalisation, though once again many do of course. It is also potentially at least, on the changing or switching therapies count, possible for a condition to remain medicalised, definitionally speaking that is, whilst undergoing some degree of depharmaceuticalisation over time in favour of other non-pharmaceutical forms of therapeutic intervention. This for example, to take a case from our own recent research on sleep medicines, might include current downward pressure on prescription hypnotics for insomnia in England today in favour of other non-pharmaceutical strategies such a good sleep hygiene and cognitive behaviour therapy (CBT) (Gabe et al. 2015, Gabe et al. 2017).

Another good example here of these variable relations between medicalisation and pharmaceuticalisation - as we have stressed in our previous publications (Williams, Martin, and Gabe 2011), including indeed the special issue on 'pharmaceuticalisation' that Busfield cites (Gabe et al. 2015) - concerns the issue of pharmaceutical enhancement amongst the otherwise 'healthy'. In her brief discussion of pharmacological enhancement, Busfield talks of the use of licit and illicit drugs for bodily improvement as an area of medical expansion, although noting that 'labels of health and illness are not routinely applied' and that these states 'may not be regarded as pathological'. If however, following Conrad (2015: vii, our emphasis), the definitional issue is key to medicalisation, and medicalisation is regarded as 'the process by which nonmedical problems become defined and treated as medical problems, usually as diseases or disorders' then this surely problematises simply equating the use of pharmaceuticals for 'improvement' in the absence of disease or disorder as yet 'another medicalisation of the body'.

To this we might add a further point, drawing from science and technology studies (STS), concerning the 're-purposing' of various medical technologies. Whilst Busfield seems to imply that any use of a medical technology is a form of medicalisation, with or without reference to labels of health and illness, the actual or potential 're-purposing' of these medical objects or technologies in everyday/night life, pharmaceuticals included, surely suggests otherwise. Consider, for instance, the domestic use of pharmaceuticals for aesthetic reasons - to gain or lose weight, to build muscle mass and so on. In these cases and others like them, pharmaceutical use becomes detached from the therapeutic context and discourses of medicine and health. What counts as an enhancement or an improvement moreover is both subjective and selective, 
and pharmaceutical use may involve gains as well as losses for the individual not only in relation to health but also socially, morally and politically.

Pharmaceuticalisation then, as this suggests, is clearly a more precise and specific concept than medicalisation; a concept which directs our attention by virtue of this specificity to pharmaceutical modes of intervention vis-à-vis other forms of medical and indeed non-medical intervention. In doing so moreover it provides a framework which allows one to focus on the technology in question, without necessarily privileging medicine, medical professionals or medical labels of health, illness, pathology and disorder (Coveney et al. 2011). Through the lens of pharmaceuticalisation, we can study the structures, institutions and collective actors that produce, market and dispense drugs (Collin 2016), in addition to exploring the meanings and practices of different forms of pharmaceutical use in everyday and every night life, across both medical and domestic contexts and the impacts of this on identities and subjectivities without always or necessarily making 'medical expansion' or 'medical' anything for that matter central to the analysis.

As Busfield notes in regard to biomedicalisation and medicalisation, each is doing different analytical work and the former cannot replace the latter. We would argue the same point in regards to pharmaceuticalisation and medicalisation. All in all then, it is indeed important to stress the analytical value of pharmaceuticalisation in our view, including the complex relations between medicalisation and pharmaceuticalisation. The two processes are not though in our view, contra Busfield, to be seen as being 'parallel' to one another. Rather, as our work suggests, although they are often overlapping, contingent and difficult to disentangle there is still analytical merit and value in doing so for the very reasons articulated above.

Here we arrive at our final point concerning what we take to be some newly emerging directions and future agendas regarding sociological work on medicalisation: agendas indeed which Busfield only briefly touches on toward the end of her paper but which are also surely important to fully consider in any rounded reassessment of the concept and its future. This for example includes Conrad and colleagues' (2010) efforts to estimate the costs of medicalisation and other new work, in keeping with our 'related' not 'alternative' point above, which is starting to explore how medicalisation, biomedicalisation and pharmaceuticalisation are not simply 'related' but 'co-evolving' processes throughout the globe (Bell and Figert 2014, 2015). More work too, in our view, could profitably be undertaken in future on: (i) the positive aspects or faces of medicalisation; (ii) processes of demedicalisation which, as Halfmann (2012) rightly argues, may in some cases occur simultaneously with medicalisation; (iii) the role of social media and new digital technologies in these changing dynamics of medicalisation and pharmaceuticalisation over time, and; (iv) the reflexive role of sociologists themselves in these medicalisation debates, albeit in ways, to repeat, that go beyond Strong's original musings on these matters. The first of these issues indeed would be particularly timely in our view, given current debates about access and rights to medical services, the role of public health and shifts in the organisation of health care taking place today. This in turn flags something that may perhaps have always been implicit if not explicit in past medicalisation research but which nevertheless, in keeping with our reflexive agendas point above, merits further discussion and debate both now and in future: namely, the manner in which these medicalisation and pharmaceuticalisation debates demand and necessitate engagement with sociology's publics in precisely the ways Burawoy (2005) envisages, thereby embodying if not exemplifying a more avowedly 'public' medical sociology in the 21 st century.

All in all then whilst we agree with Busfield that medicalisation remains a relevant and valuable sociological concept, where we seem to diverge most is in our respective assessments of the value of pharmaceuticalisation as a related yet distinct sociological concept which, as we have stressed, has variable relations with medicalisation, including the potential for 
pharmaceuticalisation beyond medicalisation. Busfield indeed on this count, it seems, is in danger perhaps of her own particular form of conflation, given pharmaceuticalisation cannot in our view, to repeat one last time, simply be collapsed into or subsumed by the concept of medicalisation; not at least without missing some potentially important dynamics and relations between these concepts in the process so to speak. We welcome Busfield's further thoughts and reflections on these matters therefore in the interests of what we hope, in the best traditions of academic life, will be a constructive, instructive and indeed productive exchange on a key concept within medical sociology, past, present and future too no doubt.

Address for correspondence: Simon Williams, Department of Sociology, University of Warwick, Coventry,CV4 7AL.UK. E-mail: s.j.williams@warwick.ac.uk

\section{References}

Abraham, J. (2010) Pharmaceuticalisation of society in context. Theoretical, empirical and health dimensions, Sociology, 44, 4, 603-22.

Bell, S. and Figert, A.E. (2014) Medicalization and pharmaceuticalization at the intersections: Looking backwards, sideways and forwards, Social Science and Medicine, 75, 5, 775-83.

Bell, S. and Figert, A.E. (2015) Reimagining (bio)medicalization, pharmaceuticals and genetics: old critiques and new engagements. London: Routledge.

Burawoy, M. (2005) For public sociology, American Sociological Review, 70, 1, 4-28.

Busfield, J. (2017) The concept of medicalisation reassessed, Sociology of Health \& Illness, doi: 10.1111/ $1467-9566.12538$.

Clarke, A., Fishman, J., Fosket, J.R., Mamo, L., et al. (2003) Biomedicalization: technoscientific transformations of health, illness and US biomedicine, American Sociological Review, 68, 2, 161-94.

Clarke, A., Mamo, L., Fosket, J., Fishman, J., et al. (2010) Biomedicalization, technoscience, health and illness in the US. Durham: Duke University Press.

Collin, J. (2016) On social plasticity: the transformative power of pharmaceuticals on health, nature and identity, Sociology of Health and Illness, 38, 1, 73-89.

Conrad, P. (1992) Medicalization and social control, Annual Review of Sociology, 18, 209-32.

Conrad, P. (2007) The nedicalization of society. On the transformation of human conditions into treatable disorders. Baltimore: Johns Hopkins University Press.

Conrad, P. (2015) Forword. In Bell, S. and Figert, A.E. (eds) Reimagining (bio)medicalization, pharmaceuticals and genetics: old critiques and new engagements. London: Routledge.

Conrad, P., Mackie, T. and Mehrotra, A. (2010) Estimating the costs of medicalization, Social Science and Medicine, 70, 12, 1943-47.

Conrad, P. and Schneider, J. (1980) Looking at levels of medicalization: A comment on Strong's critique of the thesis of medical imperialism, Social Science and Medicine, 14A, 1, 75-9.

Coveney, C., Gabe, J. and Williams, S. (2011) The sociology of cognitive enhancement: medicalisation and beyond, Health Sociology Review, 20, 4, 381-93.

Davis, C. (2015). Drugs, cancer and end-of-life care: A case study of pharmaceuticalization? Social Science and Medicine, 131, 207-14.

Gabe, J., Coveney, C. and Williams, S.J. (2016) Prescriptions and proscriptions: moralizing sleep medicines, Sociology of Health \& Illness, 38, 4, 627-44.

Gabe, J., Williams, S.J. and Coveney, C. (2017) Prescription hypnotics in the news: a study of UK audiences, Social Science and Medicine, 174, 2, 43-52.

Gabe, J., Williams, S.W., Martin, P. and Coveney, C.M. (2015) Pharmaceuticals and society: power, promises and prospects, Social Science and Medicine, 131, 193-8.

Halfmann, P. (2012) Recognising medicalisation and demedicalisation: discourses, practices and identitities, Health, 16, 2, 186-207. 
Moynihan, R., Health, I. and Henry, D. (2002) Selling sickness: the pharmaceutical industry and disease-mongering. British Medical Journal, 324, 7342, 886-91.

Moynihan, R. and Henry, D. (2006) The fight against disease mongering: generating knowledge for action, Public Library of Science - Medicine, 3, 4, e191.

Rose, N. (2007) Beyond medicalisation, The Lancet, 369, 9562, 700-2.

Strong, P. (1979) Sociological imperialism and the medical profession: a critical examination of the thesis of medical imperialism, Social Science and Medicine, 13A, 2, 199-215.

Williams, S.J. (2001) Sociological imperialism and the medical profession revisited: where are we now? Sociology of Health \& Illness, 23, 2, 135-58.

Williams, S.J. (2004) Medicine and the body. London: Sage.

Williams, S.J. and Gabe, J. (2015) Peter Conrad and the medicalisation of society. In Collyer, F. (ed) The Palgrave handbook of social theory in health, illness and medicine. Basingstoke: Palgrave Macmillan.

Williams, S., Martin, P. and Gabe, J. (2011) The pharmaceuticalisation of society? A framework for analysis, Sociology of Health and Illness 33, 5, 710-25.

Williams, S.J., Gabe, J. and Martin, P. (2012) Medicalization and pharmaceuticalization at the intersections: A commentary on Bell and Figert, Social Science and Medicine, 75, 12, 2129-30. 